\title{
Mu-Opioid Receptor Alkylation in the Ventral Pallidum and Ventral Tegmental Area, but not in the Nucleus Accumbens, Attenuates the Effects of Heroin on Cocaine Self-Administration in Rats
}

\author{
Thomas J Martin*,', Michael Coller', Conchita Co' and James E Smith' \\ 'Department of Physiology and Pharmacology, Center for the Neurobiological Investigation of Drug Abuse, Wake Forest University School of \\ Medicine, Winston-Salem, NC, USA
}

\begin{abstract}
The concurrent use of cocaine and heroin, often referred to as speedball, is a powerful reinforcer that has been reported in humans to sometimes result in heightened euphoria compared with either drug alone. Data from animal research indicate that the reinforcing efficacy of low doses of cocaine is potentiated by the addition of small amounts of heroin and that this potentiation is accompanied by synergistic increases in nucleus accumbens (NAc) extracellular fluid levels of dopamine. Although mu- and/or delta-opioid receptors may underlie this potentiation, the opioid receptor subtype or the loci responsible for this enhancement is not known. This experiment used intracranial administration of a selective mu-opioid receptor alkylating agent (beta-funaltrexamine $(\beta$-FNA)) to assess the role of $\mu$-opioid receptors in the NAc, ventral pallidum (VP), and ventral tegmental area (VTA) on the ability of heroin to alter cocaine self-administration. Rats were trained to self-administer cocaine, heroin, or their combination and were administered either vehicle or $\beta$-FNA into one of each brain region and the effects upon drug intake assessed. $\beta$-FNA administered into the VP or VTA shifted the dose-effect curve for the cocaine/heroin combination towards that maintained by cocaine alone. $\beta$-FNA had no effect on self-administration of the combination of cocaine and heroin when injected into the NAc. These data suggest that heroin may attenuate feedback inhibition from the NAc to the VP and VTA when co-self-administered with cocaine, resulting in a positive modulation of the effects of cocaine. Neuropsychopharmacology (2008) 33, I I7I - I I78; doi: I 0. I038/sj.npp. I 30 I490; published online 20 June 2007
\end{abstract}

Keywords: opioid; reinforcement; irreversible; heroin; drug abuse; dopamine

\section{INTRODUCTION}

The use of cocaine and opiate combinations represents a growing subset of intravenous drug abusers (Schütz et al, 1994) with a significant frequency of cocaine use in individuals in methadone (Magura et al, 1998) and LAAM (Craddock et al, 1997) maintenance treatment programs for opiate abuse. This co-abuse has negative consequences, as high cocaine use has been reported to decrease the likelihood of a positive treatment outcome for opiate addicts (Downey et al, 2000). This co-abuse likely results from a positive modulation of the neuronal events mediating the processes that underlie the self-administration of these drugs (reinforcement, subjective effects, etc.). The co-administration of cocaine and heroin by experi-

\footnotetext{
* Correspondence: Dr TJ Martin, Department of Physiology and Pharmacology, Wake Forest University School of Medicine, Medical Center Boulevard, Winston-Salem, NC 27|57-1083, USA, Tel: + I 336 7I6 8554, Fax: + I 336 716 850 I, E-mail: tjmartin@wfubmc.edu Received II December 2006; revised I I May 2007; accepted 24 May 2007
}

enced drug users has been reported to produce heightened euphoria compared with either drug alone (Kosten et al, 1987; Rosen and Kosten, 1991; Tutton and Crayton, 1993; Walsh et al, 1996; Wang et al, 2001). In addition, both muand delta-opioid receptor agonists have been shown to potentiate the reinforcing effects of cocaine in rats (Ranaldi and Munn, 1998) and to enhance dopaminergic action in the nucleus accumbens (NAc), which is reflected by enhanced effects of cocaine on NAc extracellular fluid levels of dopamine ([DA $\left.]_{\mathrm{e}}\right)$ (Hemby et al, 1999). The relevant brain sites in which heroin potentiates the behavioral and neurochemical effects of cocaine have not been elucidated.

There are a number of sites within the limbic reward system in which cocaine and opioids could produce additive or synergistic interactions. The dopaminergic projection neurons from the ventral tegmental area (VTA) to the NAc and ventral pallidum (VP) are thought to be essential for cocaine's reinforcing effects. Injection of opioid antagonists into the VP blocks the conditioned place preference to cocaine and the self-administration of heroin (Hubner and Koob, 1990; Skoubis and Maidment, 2003). GABAergic 
neurons in the NAc project to the VP and both GABAergic neurons and DAergic terminals within the VP contain opioid receptors (Napier and Mitrovic, 1999). Both presynaptic inputs and postsynaptic output neurons within the VP contain mu-opioid receptors, whereas delta-opioid receptors are located exclusively on postsynaptic neurons within this structure that project to the ventral striatum (Olive et al, 1997). GABA levels in microdialysates taken from the VP are decreased during heroin self-administration, suggesting that GABAergic neurons are modulated at doses of heroin that maintain self-administration (Caille and Parsons, 2004). It is not known whether the actions of opioids within the VP are necessary for the effects of heroin on cocaine self-administration, or if such interactions occur elsewhere in the limbic system such as the NAc or VTA. The present experiment was initiated to determine if the interaction between heroin and cocaine in a self-administration paradigm requires mu-opioid receptors in the NAc or the predominant targets of GABAergic projection medium spiny neurons in the VP or VTA. This was accomplished by training animals to self-administer cocaine, heroin, or cocaine/heroin combinations and assessing the effects of opioid mu-receptor alkylation with the administration of beta-funaltrexamine ( $\beta$-FNA) into the NAc, VP, or VTA on drug intake.

\section{METHODS}

\section{Subjects}

Adult male, Fisher 344 rats (Charles River, Raleigh, NC) weighing between 250 and $350 \mathrm{~g}(N=70)$ at the beginning of the experiments were used. Rats were kept on a reversed light:dark cycle (dark 1700-0500) in a temperature and humidity controlled room and given ad lib access to food and water except during experimental sessions, which were conducted during the dark cycle.

\section{Surgical Procedures}

Intravenous catheters. Rats were pretreated with atropine methyl nitrate $(10.0 \mathrm{mg} / \mathrm{kg}$; i.p.) and implanted with indwelling jugular catheters under pentobarbital anesthesia (50.0 mg/kg i.p.) using a previously described procedure (Weeks, 1972). Penicillin G procaine (75000 U; 0.25 ml, i.m.) was administered post-surgery. The catheter (Tygon tubing, S-54-HL) was anchored to tissue surrounding the external jugular vein and exited through a plastic backplate enclosed in teflon mesh, which was implanted subcutaneously between the scapulae for attachment of a leash. The catheter was enclosed in a leash (stainless steel 11-gauge tubing with steel spring on each end) that was anchored to the plastic backplate. The leash passed through the ceiling of the chamber and was attached to the single-channel fluid swivel (Brown et al, 1976), which was secured to one end of a counter-balanced arm permitting uninhibited mobility. The swivel was connected to a syringe that was operated by a syringe pump (Med Associates, St Albans, VT). The animals were housed in a cage with a counterbalance to offset the weight of the swivel and leash. Hourly infusions of $0.9 \%(w / v)$ saline with $1.7 \mathrm{U} / \mathrm{ml}$ of heparin were administered through the swivel and catheter to maintain catheter patency.
Intracranial guide cannulas. Rats were implanted with injection guide cannulas (CMA11, CMA, North Chelmsford, MA) to terminate at the dorsal surface of the NAc $(8.3 \mathrm{~mm}$ from lambda, $\pm 1.5 \mathrm{~mm}$ lateral from the midline, and $5.9 \mathrm{~mm}$ ventral from the dura, $N=12)$, VP $(7.8 \mathrm{~mm}$ from lambda, $\pm 1.7 \mathrm{~mm}$ lateral from the midline, and $5.0 \mathrm{~mm}$ ventral from the dura, $N=28)$, or the VTA $(2.2 \mathrm{~mm}$ from lambda, $\pm 1.0 \mathrm{~mm}$ lateral from the midline, and $6.1 \mathrm{~mm}$ ventral from the dura, $N=30$ ) (König and Klippel, 1967) using a stereotaxic frame (Stoelting, Wood Dale, IL). The guide cannulas were secured to the skull with stainless steel screws and dental acrylic cement and obturators (28 g) inserted to prevent blockage.

\section{Apparatus}

The animals (including swivel and counterbalance) were transferred to operant conditioning chambers (Med Associates, St Albans, VT) $(27.0 \times 21.0 \times 21.0 \mathrm{~cm})$ for the self-administration session, which were enclosed in soundattenuating, ventilated enclosures (Med Associates, St Albans, VT) containing a houselight, sonalert tone, and exhaust fan. Each chamber contained a lever $(5.5 \times 1.8 \mathrm{~cm})$ located on each of the two side walls approximately $7.5 \mathrm{~cm}$ from the grid floor and $2.1 \mathrm{~cm}$ from the front and back walls. Stimulus lights were located above each lever to indicate drug availability. Experimental sessions occurred Monday to Friday and were controlled by microcomputers using Med-PC (Med Associates, St Albans, VT) software. The lever light above the active lever was illuminated during the session except for the $20 \mathrm{~s}$ following the initiation of an infusion, during which the houselight was illuminated and the sonalert tone was activated. Upon the termination of this 20-s stimulus complex, the lever light was illuminated and infusions were once again available.

\section{Drug Self-Administration}

Rats were trained to intravenously self-administer cocaine (666, 333, and $167 \mu \mathrm{g} /$ infusion; $N=18)$, heroin $(18,9$, and $4.5 \mu \mathrm{g} /$ infusion; $N=23$ ), or cocaine/heroin combinations (cocaine/heroin-666/18, 333/9, and 167/4.5 $\mu \mathrm{g} /$ infusion; $N=29$ ) using a within session dose-intake procedure similar to that reported previously (Martin et al, 1996; Hemby et al, 1996, 1999). The self-administration sessions were $3 \mathrm{~h}$ in duration, 5 days per week with $60 \mathrm{~min}$ access to each dose and a descending order of presentation with a 10 min time out between doses. Doses were determined by the duration of pump operation $(3.1,6.2$, and $12.4 \mathrm{~s}$ resulting in injection volumes of $0.1,0.2$, and $0.4 \mathrm{ml}$, respectively). When stable patterns of self-administration were obtained (mean number of infusions delivered for each dose of cocaine, heroin, or the combination did not vary by more than $10 \%$ from the mean), the doses of the drugs were decreased by $50 \%$ sequentially over the next 10 sessions until a range of doses was found with cocaine/ heroin combinations for which the rats would only selfadminister the highest of the three available doses (167/4.5, $83.5 / 2.3$, and $41.7 / 1.1 \mu \mathrm{g} /$ infusion of cocaine/heroin). The dose range of each drug alone was adjusted in a similar manner for comparing the effects of $\beta$-FNA on the self- 
administration of each drug alone to those found with the combination (cocaine-167, 83.5, and $41.7 \mu \mathrm{g} /$ infusion; heroin $-4.5,2.3$, and $1.1 \mu \mathrm{g} /$ infusion).

\section{Administration of $\beta$-FNA}

When stable baselines of self-administration were obtained at threshold doses, the rats received bilateral injections of either $\beta$-FNA ( $2.5 \mathrm{nmol}$ in $1.0 \mu \mathrm{l}$ sterile water) or the vehicle $(1.0 \mu \mathrm{l}$ sterile water) (delivered over $5 \mathrm{~min}$ at a rate of $0.2 \mu \mathrm{l} /$ min) into the VP or NAc with a 28-gauge injection cannula through the guide cannulas. This dose of $\beta$-FNA has been previously shown to be selective for mu-opioid receptors in the NAc (Martin et al, 2002). In the VTA, $1 \mathrm{nmol}$ of $\beta$-FNA was administered bilaterally in a volume of $0.3 \mu \mathrm{l}$ in a similar manner. Intracranial injections were performed on Mondays to allow for cocaine and/or heroin to be eliminated over the weekends and animals were not allowed to self-administer drugs until $24 \mathrm{~h}$ after $\beta$-FNA or vehicle administration. Animals were allowed to self-administer cocaine, heroin, or cocaine/heroin combinations for at least 2 weeks following intracranial treatment or until behavior returned to baseline levels.

\section{Histology}

Animals were killed by decapitation under pentobarbital anesthesia and the brains were removed and frozen at $-80^{\circ} \mathrm{C}$. Frozen brains were warmed to $-20^{\circ} \mathrm{C}$ and sections $(20 \mu \mathrm{m})$ were taken using a cryostat. The cannula track and placement were verified with microscopy following fixation and staining (Klüver and Barrera, 1953).

\section{Drugs and Chemicals}

Cocaine hydrochloride and heroin hydrochloride were obtained from the Drug Supply Program of the National Institute on Drug Abuse. Pentobarbital was purchased from Abbott Laboratories (North Chicago, IL), sodium heparin from Elkin-Sinn (Cherry Hill, NJ), methyl atropine nitrate from Sigma Chemical Co. (St Louis, MO), penicillin G procaine from Butler Vet (Columbus, $\mathrm{OH}$ ) and $\beta$-FNA from Research Biochemicals Inc. (Natick, MA).

\section{Data Analysis}

Data were analyzed by two-way ANOVA with drug dose and day following intracranial treatment serving as the independent variables and number of infusions serving as the dependent measures, comparing pretreatment baseline data to post-treatment data for animals treated with $\beta$-FNA or vehicle. Post hoc analyses were performed using the Bonferroni/Dunn method for multiple comparisons to a control, with pretreatment baseline data serving as the control for each treatment group.

\section{RESULTS}

\section{Cocaine, Heroin, and Speedball Self-Administration}

Intravenous infusions of cocaine, heroin, and cocaine/ heroin combinations maintained self-administration in a dose-related manner for all groups (Figures 1-3). The initial dose range for cocaine/heroin was 666/18, 333/9, and $167 / 4.5 \mu \mathrm{g} /$ infusion, which maintained rates of $4.9 \pm 0.3$, $8.0 \pm 0.4$, and $15.1 \pm 0.8 \mathrm{infusions} / \mathrm{h}$, respectively. Lowering the dose range to $333 / 9,167 / 4.5$, and $83.5 / 2.3 \mu \mathrm{g} /$ infusion resulted in $8.9 \pm 0.4,15.1 \pm 0.6$, and $25.5 \pm 1.4$ infusions/h, respectively. Lowering the range of cocaine/heroin doses to the final range of $167 / 4.5,83.5 / 2.3$, and $41.8 / 1.2 \mu \mathrm{g} /$ infusion resulted in an ascending dose-effect curve with $13.8 \pm 0.6$, $6.3 \pm 1.7$, and $3.8 \pm 0.8$ infusions/h, respectively. Substitution of saline for cocaine/heroin resulted in five or fewer infusions being delivered in each hourly component (data not shown).
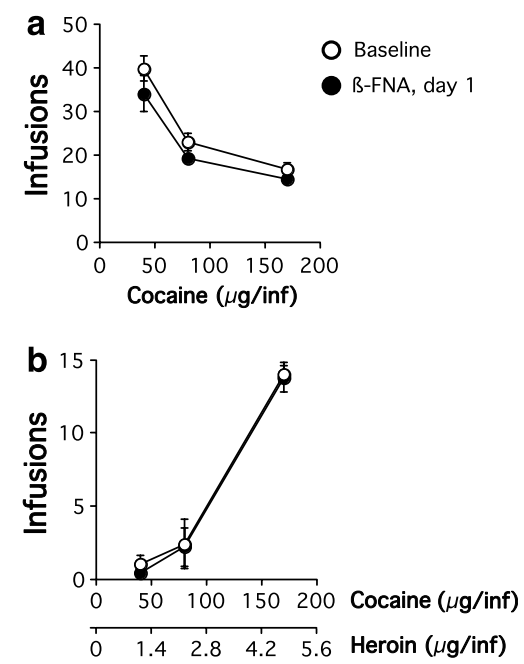

Figure I Dose-effect curves for threshold doses of (a) cocaine, or (b) cocaine/heroin combinations for rats that received $\beta$-FNA injection into the NAc. Baseline data were averaged over the five sessions immediately preceding $\beta$-FNA administration.

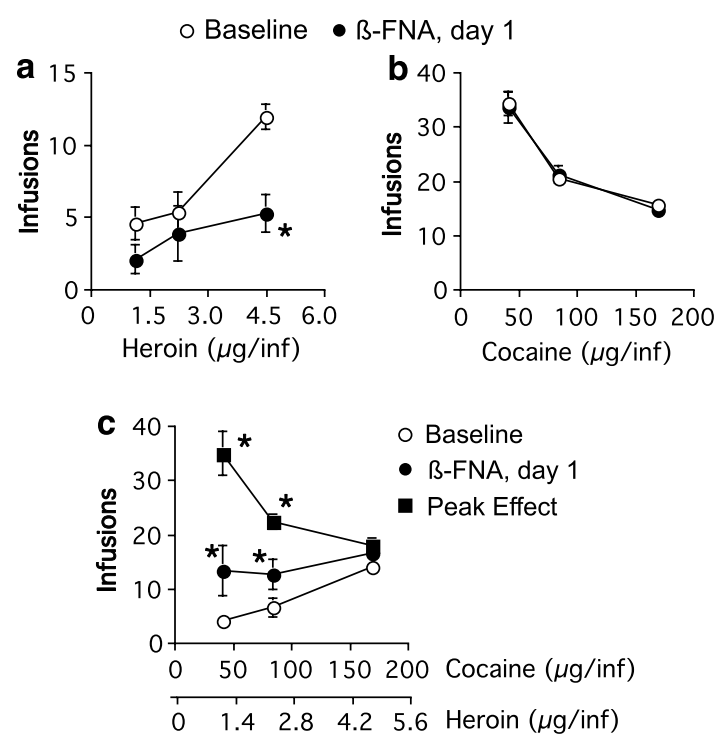

Figure 2 Dose-effect curves for threshold doses of (a) heroin, (b) cocaine, or (c) cocaine/heroin combinations for rats that received $\beta$-FNA injection into the VP. Baseline data were averaged over the five sessions immediately preceding $\beta$-FNA administration, *significantly different from baseline, $p<0.05$. 

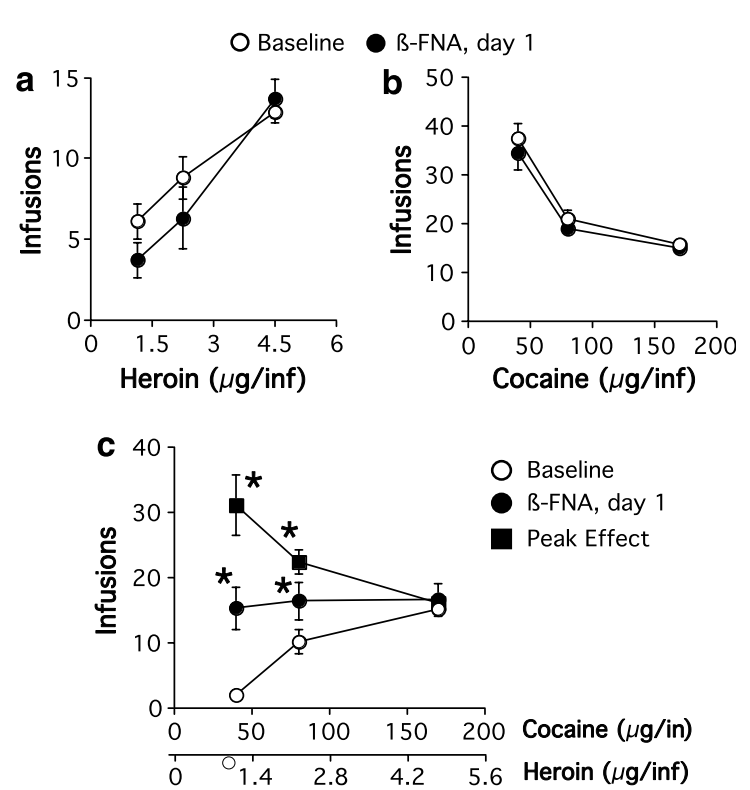

Figure 3 Dose-effect curves for threshold doses of (a) heroin, (b) cocaine, or (c) cocaine/heroin combinations for rats that received $\beta$-FNA injection into the VTA. Baseline data were averaged over the five sessions immediately preceding $\beta$-FNA administration, *significantly different from baseline, $p<0.05$.

Initial training of cocaine self-administration used doses of 666,333 , and $167 \mu \mathrm{g} /$ infusion of cocaine and resulted in $6.3 \pm 0.3,10.0 \pm 0.4$, and $18.3 \pm 0.7$ infusions/h, respectively. Lowering the cocaine doses to a range of 333,167 , and $83.5 \mu \mathrm{g} /$ infusion resulted in $8.9 \pm 2.0,12.5 \pm 2.8$, and $20.8 \pm 4.8$ infusions/h, respectively. Lowering the range to the final doses of $167,83.5$, and $41.7 \mu \mathrm{g} /$ infusion corresponding to those doses used in combination with heroin resulted in a descending dose-effect curve with baseline rates of $15.4 \pm 1.0,20.3 \pm 1.0$, and $34.2 \pm 2.2$ infusions $/ h$, respectively (Figure 2). Substitution of saline for cocaine resulted in five or fewer infusions being administered during each hourly component for each drug (data not shown).

The initial doses of heroin used to engender and maintain responding also resulted in a descending limb of the doseeffect curve. Doses of 18,9 , and $4.5 \mu \mathrm{g} /$ infusion resulted in $3.9 \pm 0.6,5.5 \pm 0.9$, and $9.7 \pm 1.3$ infusions/h. Lowering the dose range to $9,4.5$, and $2.3 \mu \mathrm{g} /$ infusion resulted in $6.6 \pm 1.2$, $7.3 \pm 0.9$, and $11.7 \pm 1.3$ infusions/h, respectively. As with the cocaine/heroin combinations, the final dose range of heroin was $4.5,2.3$, and $1.2 \mu \mathrm{g} /$ infusion and yielded an ascending limb with $11.9 \pm 0.9,5.3 \pm 1.4$, and $4.5 \pm 1.1$ infusions/h, respectively (Figure 3 ). As with the cocaine/ heroin and cocaine groups, substitution of saline for heroin resulted in five or fewer infusions being administered in each of the three hourly components (data not shown).

\section{Effects of $\beta$-FNA Administration into the NAc}

Cocaine self-administration. Injection of $\beta$-FNA into the NAc did not influence responding maintained by cocaine (Figure $1, N=6$ ). There was no significant effect on cocaine intake with time following $\beta$-FNA treatment $(\mathrm{F}(9,179)=1.1$, $p=0.4)$ and no significant interaction between time

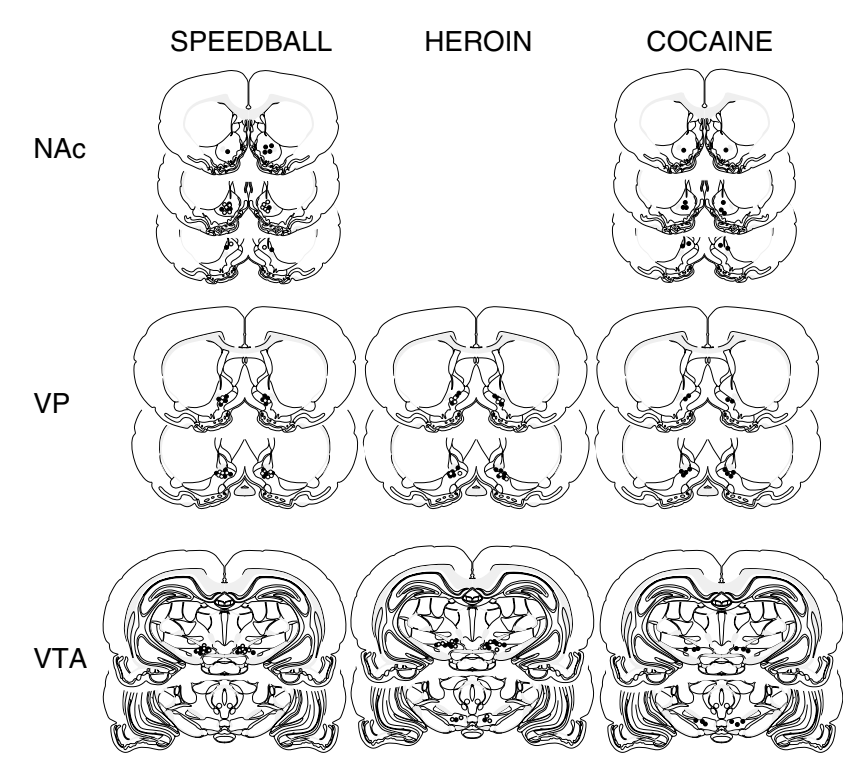

Figure 4 Injection sites for $\beta$-FNA or saline administration into the NAc, VP, or VTA for rats whose data are depicted in Figures $1-3$.

following $\beta$-FNA and cocaine dose $(\mathrm{F}(18,179)=0.3$, $p=1.0)$. Cocaine self-administration was dose-responsive at all times following $\beta$-FNA treatment $(\mathrm{F}(2,179)=134.4$, $p<0.0001)$. The injection sites within the NAc are shown in Figure 4 .

Speedball self-administration. Injection of $\beta$-FNA into the NAc also did not influence responding maintained by cocaine/heroin combinations (Figure $1, N=6$ ). Self-administration of cocaine/heroin did not change from baseline at any time point following $\beta$-FNA injection $(\mathrm{F}(9,179)=1.7$, $p=0.1)$ and there was no significant interaction between day after $\beta$-FNA administration and cocaine/heroin dose $(\mathrm{F}(18,179)=0.6, p=0.9)$. Self-administration of cocaine/ heroin was dose-responsive following $\beta$-FNA administration $(\mathrm{F}(2,179)=41.4, p<0.0001)$. The injection sites for these animals within the NAc are shown in Figure 4.

\section{Effects of $\beta$-FNA Administration into the VP}

Heroin self-administration. Administration of $\beta$-FNA into the VP significantly attenuated heroin self-administration $(\mathrm{F}(9,177)=2.32, p=0.02)$, producing a flattening of the dose-effect curve (Figure 2, N=6). The highest dose of heroin was affected for 2 days following $\beta$-FNA administration, after which behavior returned to baseline levels. Administration of saline was without effect at any time point $(\mathrm{F}(9,149)=1.2, p=0.28, N=5)$. The injection sites for the VP are shown in Figure 4.

Cocaine and speedball self-administration. Cocaine selfadministration was not altered by administration of $\beta$-FNA into the VP at any time point $(\mathrm{F}(9,177)=1.7, p=0.99$, $N=6)$. There was also no significant effect when only the baseline data and the data obtained $24 \mathrm{~h}$ after $\beta$-FNA administration were compared $(\mathrm{F}(1,35)=0.1, p=0.76)$, which was the time point giving the maximum effect on heroin self-administration (Figure 2). In contrast, administration of $\beta$-FNA into the VP produced a significant effect 
on the self-administration of cocaine/heroin combinations resulting in a pattern of intake no different than cocaine alone $(\mathrm{F}(9,299)=2.1, p=0.03)$ (Figure 2, $N=6)$. The effect was variable between animals with respect to time after $\beta$ FNA administration. The peak effect of $\beta$-FNA occurred at $6.6 \pm 1.5$ days after administration (range 2-9 days). The recovery period following the establishment of the peak effect of $\beta$-FNA was likewise variable and was $5.4 \pm 0.6$ days $(12.0 \pm 1.7$ days after administration of $\beta$-FNA). At the time of the peak effect, the dose-effect curve for the selfadministration of cocaine/heroin combinations was not significantly different than cocaine alone $(p>0.05)$ (Figure 2). $\beta$-FNA shifted the dose-effect curve from ascending to descending for cocaine/heroin combinations at the time of peak effect $(\mathrm{F}(1,59)=117, p<0.0001)$ and the effect was dependent upon the dose of cocaine/heroin available $(\mathrm{F}(2,59)=24.3, p<0.0001)$. Administration of saline had no effect on cocaine/heroin self-administration at any time point $(\mathrm{F}(9,149)=0.7, p=0.73, N=5)$. The injection sites within the VP are depicted in Figure 4.

\section{Effects of $\beta$-FNA Administration into the VTA}

Heroin self-administration. Injection of $\beta$-FNA into the VTA did not produce an effect on heroin self-administration over the range of doses used at any time following $\beta$-FNA treatment $(\mathrm{F}(9,179)=0.4, p=0.95)$ and there was no significant interaction between heroin dose and time after $\beta$-FNA treatment $(\mathrm{F}(18,179)=0.8, p=0.7)$ (Figure 3, $N=6$ ). Heroin self-administration was dose-responsive at all time points following $\beta$-FNA treatment $(\mathrm{F}(2,179)=31.3$, $p<0.0001)$. Injection of saline into the VTA likewise had no effect on heroin self-administration and there was no significant interaction between days after saline administration and heroin dose $(\mathrm{F}(9,179)=0.5, p=0.9$ and $\mathrm{F}(18,179)=0.3$, $p=1.0$, respectively, $N=6$ ) (data not shown). The injection sites within the VTA are shown in Figure 4.

Cocaine self-administration. As with heroin self-administration, injection of $\beta$-FNA into the VTA did not influence responding maintained by cocaine (Figure $3, N=6$ ). There was no significant effect on cocaine intake with time following $\beta$-FNA treatment $(\mathrm{F}(9,179)=1.5, p=0.2)$ and no significant interaction between time following $\beta$-FNA and cocaine dose $(\mathrm{F}(18,179)=0.3, p=1.0)$. Cocaine self-administration was dose-responsive at all times following $\beta$-FNA treatment $(\mathrm{F}(2,179)=163.3, p<0.0001)$. Injection of saline into the VTA had no effect on cocaine intake at any dose or time following injection $(\mathrm{F}(9,179)=0.6, p=0.9$ and $\mathrm{F}(18,179)=0.3, p=1.0$, respectively) (data not shown). The injection sites within the VTA are shown in Figure 4.

Speedball self-administration. Injection of $\beta$-FNA into the VTA produced similar results as when it was injected into the VP. $\beta$-FNA increased the number of infusions of cocaine/heroin at the two lowest doses $24 \mathrm{~h}$ after administration $(\mathrm{F}(1,35)=4.7, p=0.03, N=6)$ producing initially a flat dose-effect curve similar to that obtained following injection into the VP (Figures 2 and 3). The effect was dependent upon the time after $\beta$-FNA administration $(\mathrm{F}(9,179)=2.9, p=0.004)$. Similar to the data obtained from animals following injection of $\beta$-FNA into the VP, the time to the peak effect of $\beta$-FNA injection into the VTA on the self-administration of cocaine/heroin was variable between animals and occurred $3.8 \pm 1.0$ days after administration (range 1-7 days). At the time of peak effect, $\beta$-FNA produced responding for cocaine/heroin that was significantly different from baseline $(\mathrm{F}(1,35)=43.7, p<0.0001)$ and there was a significant interaction between the effect of $\beta$-FNA administration and cocaine/heroin dose $(\mathrm{F}(2,35)=14.8, p<0.0001) . \beta$-FNA injected into the VTA produced a dose-response curve for cocaine/heroin selfadministration at the time of peak effect that was not significantly different than that obtained with cocaine alone $(p>0.05)$, similar to the results found following injection of $\beta$-FNA into the VP (Figures 2 and 3). Following establishment of the peak effect, responding for cocaine/heroin returned to baseline levels over $5.3 \pm 1.0$ days $(9.2 \pm 0.4$ days after $\beta$-FNA administration). Injection of saline into the VTA had no significant effect on cocaine/heroin selfadministration $(\mathrm{F}(9,209)=1.3, p=0.2, N=6)$ and there was no interaction between saline injection and cocaine/ heroin dose $(\mathrm{F}(18,209)=0.5, p=0.9)$ (data not shown). The injection sites within the VTA are shown in Figure 4.

\section{DISCUSSION}

The most important findings reported here indicate that heroin alters the rate of cocaine intake when selfadministered concurrently through mu-opioid receptors within the VP and VTA, but not the NAc. Mu-opioid receptors are contained on the medium spiny GABAergic afferents projecting from the NAc to the VP, and presumably decrease GABAergic feedback inhibition from the NAc. It is hypothesized that heroin decreases the release of GABA from the medium spiny projection neurons presynaptically in the VP through mu-opioid receptors, thereby decreasing feedback inhibition of the VP that in turn sends dopaminergic fibers to the NAc. It is further hypothesized that the mu-opioid receptors inhibit GABAergic interneurons locally in the VTA, such that heroin decreases GABAergic tone in the VTA thereby increasing DAergic tone in the NAc. The effect of $\beta$-FNA administered into the VTA would therefore be explained by decreasing the inhibitory effects of heroin on GABA in the VTA (ie, increasing GABA release in the VTA during heroin/cocaine relative to saline injected animals). The rate of cocaine/ heroin intake in combination is hypothesized to become similar to that of cocaine alone when the inhibition of GABAergic nerve endings in the VP or of local interneurons in the VTA by heroin is prevented by $\beta$-FNA treatment, thereby removing the modulatory influence of co-selfadministered heroin on cocaine intake.

The brain processes that underlie the self-administration of low doses of cocaine is enhanced by the addition of small amounts of heroin, and isobolographic analysis indicates an additive interaction for this combination at or near the threshold for maintaining self-administration for these two drugs (Smith et al, 2006). The research reported here indicates that mu-opioid receptors in the VP and VTA are necessary for the effects of heroin on cocaine selfadministration. The dose-effect curve for the self-administration of the cocaine/heroin combination at the doses 
studied was similar to that maintained by heroin alone (Figures 2 and 3). However, alkylation of mu-opioid receptors within the VP or VTA shifted the dose-effect curve for the cocaine/heroin combinations to resemble that of cocaine alone and this effect occurred over several days. The variable time course of the effect of $\beta$-FNA on the self-administration of cocaine/heroin combinations could result from acquisition of a response to a novel-reinforcing stimulus. Heroin likely produces subjective effects by acting on several brain regions in addition to the VP or VTA, and these effects potentially modify the stimulus properties of cocaine, which could include reinforcement. The recovery from the effects of $\beta$-FNA was slower for the selfadministration of the cocaine/heroin combinations than for heroin, suggesting that perhaps reacquisition of the original reinforcing stimulus occurred upon replenishment of mu-opioid receptors. It has been suggested that concurrent self-administration of cocaine and heroin produces distinct stimuli from those associated with cocaine or heroin alone (Negus et al, 1998). These data indicate that activation of mu-opioid receptors within the VP and/or VTA are necessary for heroin to alter the doseeffect curve for self-administration of low doses of cocaine in combination in rats.

The present data suggest that inactivation of mu-opioid receptors within the VP by the dose of $\beta$-FNA administered is insufficient to alter the properties of cocaine that underlie self-administration. Enkephalin content in the VP arises almost exclusively from the medium spiny GABAergic projections from the NAc (Zaborszky et al, 1985; Zhou et al, 2003). The lack of effect by $\beta$-FNA suggests that this enkephalinergic tone within the VP is not critical for cocaine's rewarding effects in the present paradigm. However, opioid receptor antagonists alter cocaine selfadministration in other paradigms. However, reinstatement of cocaine-seeking is attenuated by administration of the mu-antagonist CTOP into the VP, and morphine given directly into the VP reinstates cocaine-seeking behavior in rats (Tang et al, 2005). Administration of $\beta$-FNA into either the NAc or VTA decreased cocaine self-administration under a progressive ratio schedule of reinforcement for several sessions (Ward et al, 2004). In addition, systemic administration of opiate antagonists attenuated cocaineinduced increases in NAc $[\mathrm{DA}]_{\mathrm{e}}$ (Hooks et al, 1992) and cocaine administration increased mu-opioid receptor mRNA in the NAc (Azaryan et al, 1996). In addition, pretreatment with naltrexone decreased intravenous cocaine self-administration (Carroll et al, 1986; Corrigall and Coen, 1991; Glick et al, 1995) and suppressed acquisition of self-administration in rodents (Ramsey and van Ree, 1991). The involvement of mu-opioid receptors in the VP in the reinforcing effects of cocaine appears to be less important than these other regions.

Within the VTA, mu-opioid receptors are located predominantly on non-dopaminergic neurons (Garzon and Pickel, 2001). Recently, the electrophysiological properties of GABAergic interneurons and their response to locally applied mu-agonist or systemic heroin verified that muopioid receptors decrease firing on dendrites, and that these processes form tight gap junctions with DAergic projection neurons within the VTA (Steffensen et al, 2006). Mu-opioid receptors have also been localized to distal dendrites of projection neurons arising from the VTA and extending to the medial prefrontal cortex (Svingos et al, 2001). As cocaine inhibits the reuptake of DA released from VTA projection neurons, it is likely that inhibition of GABAergic interneurons within the VTA is a mechanism by which coself-administered heroin alters the reinforcing properties of cocaine. It is hypothesized that the effects of $\beta$-FNA injected into the VTA on cocaine/heroin self-administration is therefore due to release of these GABAergic interneurons from heroin's inhibitory effects through irreversible blockade of mu-opioid receptors. This mechanism seems more likely to play a role rather than presynaptic inhibition of projection neurons from the VTA to prefrontal cortex; however, the involvement of these neurons cannot be discounted from the present data.

The effects of $\beta$-FNA on heroin self-administration are consistent with those reported previously (Martin et al, $1995,1998,2002)$. The site of $\beta$-FNA administration within the NAc is a relevant variable when examining the involvement of mu-opioid receptors in heroin self-administration, with administration into caudal subregions producing more robust effects than administration into the rostral pole (Martin et al, 2002). In the present study, mu-FNA was administered into the mid-VP and VTA and it appears that these regions are somewhat less involved in the reinforcing effects of heroin compared with the NAc, as more robust effects on heroin self-administration were found following administration of $\beta$-FNA into the caudal $\mathrm{NAc}$ and with a longer duration of action compared with the present data (Martin et al, 2002). The relative short duration of action of $\beta$-FNA in the present study could be the result of an increased mu-opioid receptor reserve in the VP relative to the NAc. Alternatively, activation of mu-opioid receptors within the VP by heroin may produce a relatively modest effect on behavior compared with activation of muopioid receptors within the NAc. Heroin self-administration would therefore be less susceptible to manipulation by the alkylation of mu-opioid receptors in the VP or VTA, which is consistent with the data presented here.

Electrophysiological evidence indicates that mu-opioid receptor activation within the VP diminishes GABAergic and DAergic inhibitory responses while enhancing glutamatergic excitatory responses. Electrical stimulation of the VTA resulted in DA release in the VP that was attenuated by microiontophoretic application of DAMGO into the VP (Mitrovic and Napier, 2002). The predominant effect of VTA stimulation was to decrease neuronal firing within the VP (Mitrovic and Napier, 2002). Electrical stimulation of the NAc resulted in GABAergic-mediated inhibition of neuronal firing within the VP, and this inhibition was reduced by microiontophoretic application of DAMGO into the VP (Napier and Mitrovic, 1999). Administration of DAMGO into the VP potentiated the ability of glutamate to elicit excitatory post-synaptic potentials in projection neurons, but did not appear to influence glutamate release from glutamatergic fibers from the amygdala or medial prefrontal cortex (Mitrovic and Napier, 1998). The present data would seem to indicate that at least some of these neurochemical alterations by mu-opioid receptor stimulation in the VP and VTA are relevant to the ability of heroin to modify the brain processes that underlie cocaine self-administration. 
In conclusion, mu-opioid receptors in the VP or VTA appear to be necessary for the ability of heroin to alter cocaine self-administration. We hypothesize that heroin alters cocaine reinforcement with co-self-administration by inhibiting GABAergic projection neurons from the NAc to the VP through mu-opioid receptors in the VP and local GABAergic interneurons in the VTA. Previous findings indicating that diminished mu-opioid receptor activation in the VP is correlated with a negative affective state strengthens the notion that this receptor population is pertinent for the study of reinforcement mechanisms (Zubieta et al, 2003). Future studies using DAergic, GABAergic, or glutamatergic antagonists or assessment of these neurotransmitter levels in the VP or VTA by microdialysis during cocaine/heroin selfadministration could assist in understanding the relevant mechanisms related to mu-opioid receptor activation in these regions and reinforcement resulting from cocaine/heroin combinations.

\section{ACKNOWLEDGEMENTS}

The conduct of this experiment was consistent with the ethical standards outlined in Principles of laboratory animal care (NIH publication No. 80-23, revised 1996). This research was supported by Grants from the National Institute on Drug Abuse: DA 12498, DA 06634, DA 03628, and DA00114 (to JES) and from the National Institute on Neurodegenerative Disorders and Stroke: NS38231 (to TJM).

\section{DISCLOSURE/CONFLICT OF INTEREST}

The authors declare that, except for income received from their primary employer, no financial support or compensation has been received from any individual or corporate entity over the past 3 years for research or professional service and there are no personal financial holdings that could be perceived as constituting a potential conflict of interest.

\section{REFERENCES}

Azaryan AV, Clock BJ, Cox BM (1996). Mu opioid receptor mRNA in nucleus accumbens is elevated following dopamine receptor activation. Neurochem Res 21: 1411-1415.

Brown ZW, Amit Z, Weeks JR (1976). Simple flow-thru swivel for infusions into unrestrained animals. Pharmacol Biochem Behav 5: 363-365.

Caille S, Parsons LH (2004). Intravenous heroin self-administration decreases GABA efflux in the ventral pallidum: an in vivo microdialysis study in rats. Eur J Neurosci 20: 593-596.

Carroll ME, Lac ST, Walker MJ, Kragh R, Newman T (1986). Effects of naltrexone on intravenous cocaine self-administration in rats during food satiation and deprivation. J Pharmacol Exp Ther 238: $1-7$.

Corrigall WA, Coen KM (1991). Opiate antagonists reduce cocaine but not nicotine self-administration. Psychopharmacol 104: 167-170.

Craddock SG, Rounds-Bryant JL, Flynn PM, Hubbard RL (1997). Characteristics and pretreatment behaviors of clients entering drug abuse treatment: 1969 to 1993. Am J Drug and Alcohol Abuse 23: 43-59.

Downey KK, Helmus TC, Schuster CR (2000). Treatment of heroindependent poly drug abusers with contingency management and buprenorphine maintenance. Exp Clin Psychopharmacol 8: 176-184.

Garzon M, Pickel VM (2001). Plasmalemmal mu-opioid receptor distribution mainly in nondopaminergic neurons in the rat ventral tegmental area. Synapse 41: 311-328.

Glick SD, Maisonneuve IM, Raucci J, Archer S (1995). Kappa opioid inhibition of morphine and cocaine self-administration in rats. Brain Res 681: 147-152.

Hemby SE, Dworkin SI, Smith JE (1996). The effect of eticlopride and naltrexone on responding maintained by food, cocaine, heroin and cocaine/heroin combinations in rats. J Pharmacol Exp Ther 277: 1247-1258.

Hemby SE, Co C, Dworkin SI, Smith JE (1999). Synergistic elevations in nucleus accumbens extracellular dopamine concentrations during 'speedball' self-administration in rats. J Pharmacol Exp Ther 288: 274-280.

Hooks MS, Colvin AC, Juncos JL, Justice Jr JB (1992). Individual differences in basal and cocaine-stimulated extracellular dopamine in the nucleus accumbens using quantitative microdialysis. Pharmacol Biochem Behav 42: 765-770.

Hubner CB, Koob GF (1990). The ventral pallidum plays a role in mediating cocaine and heroin self-administration in the rat. Brain Res 508: 20-29.

Kluver H, Barrera EA (1953). A method for the combined staining of cell and fibers in the nervous system. J Neuropathol Exp Neurol 12: 400-403.

König JFR, Klippel RA (1967). In: Robert E (ed). The Rat Brain. Krieger Publishing Co: New York.

Kosten TR, Rounsaville BJ, Kleber HD (1987). A 2.5 year follow-up of cocaine use among treated opioid addicts. Arch Gen Psychiatry 44: 281-284.

Magura S, Kang SY, Nwakeze PC, Demsky S (1998). Temporal patterns of heroin and cocaine use among methadone patients. Subst Use Misuse 33: 2441-2467.

Martin TJ, deMontis MG, Kim SA, Sizemore GM, Dworkin SI, Smith JE (1998). Effects of $\beta$-funaltrexamine on dose-effect curves for heroin self-administration in rats: comparison with alteration of [3H]DAMGO binding to rat brain sections. Drug Alcohol Depend 52: 135-147.

Martin TJ, Walker LE, Sizemore GM, Smith JE, Dworkin SI (1996). Within-session determination of dose-response curves for heroin self-administration in rats: comparison with betweensession determination and effects of naltrexone. Drug Alcohol Depend 41: 93-100.

Martin TJ, Dworkin SI, Smith JE (1995). Alkylation of $\mu$-opioid receptors by $\beta$-funaltrexamine in vivo: correlation of the effects of in situ binding and heroin self-administration in rats. $J$ Pharmacol Exp Ther 272: 1135-1140.

Martin TJ, Kim SA, Lyupina Y, Smith JE (2002). Differential involvement of mu-opioid receptors in the rostral versus caudal nucleus accumbens in the reinforcing effects of heroin in rats: evidence from focal injections of $\beta$-funaltrexamine. Psychopharmacol 161: 152-159.

Mitrovic I, Napier TC (2002). Mu and kappa opioid agonists modulate ventral tegmental area input to the ventral pallidum. Eur J Neurosci 15: 257-268.

Mitrovic I, Napier TC (1998). Substance P attenuates and DAMGO potentiates amygdala glutamatergic neurotransmission within the ventral pallidum. Brain Res 792: 193-206.

Napier TC, Mitrovic I (1999). Opioid modulation of ventral pallidal inputs. Ann NY Acad Sci 877: 176-201.

Negus SS, Gatch MB, Mello NK (1998). Discriminative stimulus effects of a cocaine/heroin 'speedball' combination in Rhesus monkeys. J Pharmacol Exp Ther 285: 1123-1136.

Olive MF, Anton B, Micevych P, Evans CJ, Maidment NT (1997). Presynaptic versus postsynaptic localization of $\mathrm{mu}$ and delta opioid receptors in dorsal and ventral striatopallidal pathways. J Neurosci 17: 7471-7479. 
Ramsey NF, van Ree JM (1991). Intracerebroventricular naltrexone treatment attenuates acquisition of intravenous cocaine selfadministration in rats. Pharmacol Biochem Behav 40: 807-810.

Ranaldi R, Munn E (1998). Polydrug self-administartion in rats: cocaine-heroin is more rewarding than cocaine-alone. Neuroreport 9: 2463-2466.

Rosen MI, Kosten TR (1991). Buprenorphine: beyond methadone? Hosp Comm Psychiatry 42: 347-349.

Schütz CG, Vlahov D, Anthony JC, Graham NMH (1994). Comparison of self-reported injection frequencies for past 30 days and 6 months among intravenous drug users. J Clin Epidemiol 47: 191-195.

Skoubis PD, Maidment NT (2003). Blockade of ventral pallidal opioid receptors induces a conditioned place aversion and attenuates acquisition of cocaine place preference in the rat. Neuroscience 119: 241-249.

Smith JE, Co C, Coller MD, Hemby SE, Martin TJ (2006). Selfadministered heroin and cocaine combinations in the rat: additive reinforcing effects-supra-additive effects on nucleus accumbens extracellular dopamine. Neuropsychopharmacology 31: 139-150.

Steffensen SC, Stobbs SH, Colago EE, Lee RS, Koob GF, Gallegos RA et al (2006). Contingent and non-contingent effects of heroin on mu-opioid receptor-containing ventral tegmental area GABA neurons. Exp Neurol 202: 139-151.

Svingos AL, Garzon M, Colago EE, Pickel VM (2001). Mu-opioid receptors in the ventral tegmental area are targeted to presynaptically and directly modulate mesocortical projection neurons. Synapse 41: 221-229.

Tang XC, McFarland K, Cagle S, Kalivas PW (2005). Cocaineinduced reinstatement requires endogenous stimulation of mu-opioid receptors in the ventral pallidum. J Neurosci 25: 4512-4520.

Tutton CS, Crayton JW (1993). Current pharmacotherapies for cocaine abuse: a review. J Addict Dis 12: 109-127.

Walsh SL, Sullivan JT, Preston KL, Garner JE, Bigelow GE (1996). Effects of naltrexone on response to intravenous cocaine, hydromorphone and their combinations in humans. J Pharmacol Exp Ther 279: 524-538.

Wang NS, Brown VL, Grabowski J, Meisch RA (2001). Reinforcement of orally delivered methadone, cocaine and methadonecocaine combinations in rhesus monkeys: are the combinations better reinforcers? Psychopharmacol 156: 63-72.

Ward SJ, Martin TJ, Roberts DCS (2004). Beta-funaltrexamine affects cocaine self-administration in rats responding on a progressive ratio schedule of reinforcement. Pharmacol Biochem Behav 75: 301-307.

Weeks JR (1972). Long-term intravenous infusions. In: Myers RD (ed). Methods in Psychobiology 2. Academic Press: New York. pp 155-168.

Zaborszky L, Alheid GF, Beinfeld MC, Eiden LE, Heimer L, Palkovits M (1985). Cholecystokinin innervation of the ventral striatum: a morphological and radioimmunological study. Neuroscience 14: 427-453.

Zhou L, Furuta T, Kaneko T (2003). Chemical organization of projection neurons in the rat accumbens nucleus and olfactory tubercle. Neuroscience 120: 783-798.

Zubieta JK, Ketter TA, Bueller JA, Xu Y, Kulborun MR, Young EA et al (2003). Regulation of human affective responses by anterior cingulate and limbic mu-opioid neurotransmission. Arch Gen Psychiatry 60: 1145-1153. 